\title{
IMPLEMENTASI DAKWAH ISLAM MELALUI SENI MUSIK ISLAMI (Studi Deskriptif Pada Grup Nasyid EdCoustic)
}

\author{
Luki Agung Lesmana P, \\ A. Toto Suryana, Edi Suresman \\ Program Studi Ilmu Pendidikan Agama Islam, \\ Fakultas Pendidikan Ilmu Pengetahuan Sosial, Universitas Pendidikan Indonesia \\ Email:luki_alp@yahoo.co.id
}

\begin{abstract}
ABSTRAK
Penulisan artikel ini dilatarbelakangi oleh kurangnya respons remaja terhadap majelis ilmu. Penyebabnya adalah minimnya inovasi dalam pelaksanaannya, sehingga membuat seseorang enggan mengikutinya. Kondisi ini diperparah dengan banyaknya kasus yang menyeret beberapa nama da'i. Hal ini akan berimbas kepada keberlangsungan dakwah serta rusaknya generasi muda Islam di masa yang akan datang. Maka dari itu nasyid lahir sebagai wujud inovasi dalam pelaksanaan dakwah Islam. Penelitian ini betujuan untuk mengetahui bagaimana perencanaan, pengor-ganisasian, pelaksanaan, serta keberhasilan dakwah Islam melalui seni musik Islami pada nasyid EdCoustic. Metode yang digunakan adalah metode deskriptif dengan pendekatan kualitatif. Teknik pengumpulan datanya melalui observasi, wawancara, dan studi dokumentasi. Teknik analisis data dengan cara reduksi data, display data, dan disimpulkan. Hasil penelitian menyebutkan bahwa perencanaan dakwah EdCoustic sudah baik karena terdapat landasan dakwah yang jelas, dakwahnya memiliki manfaat, didukung keilmuan yang mumpuni, memiliki analisis dakwah jangka panjang serta penentuan waktu, lokasi, biaya, materi dan metode dakwahnya. Pengorganisasian dakwah EdCoustic dikatakan sudah baik karena terdapat pembagian tugas yang jelas, penentuan orang dalam pelaksanaan tugasnya, menetapkan objek dakwahya dan membentuk kerjasama dengan para da'i lainnya. Lalu pelaksanaan dakwah EdCoustic pun sudah baik karena mencakup nilai-nilai spiritual, pemikiran, material, penguasaan lapangan dan gerakan dakwah. Namun terdapat satu hal yang disayangkan, yakni kurangnya pembukuan administrasi manajemennya. Sementara itu keberhasilan dakwah EdCoustic dikatakan berhasil karena banyaknya respons positif dari pendengar, perubahan positif pada pendengar serta beberapa penghargaan yang EdCoustic raih selama berkiprah dalam dunia dakwahnya melalui seni musik Islami.
\end{abstract}

Kata Kunci: Dakwah, Seni Musik Islami, Nasyid 


\section{PENDAHULUAN}

Di zaman modern saat ini banyak sekali remaja di Indonesia yang menggandrungi trend budaya Barat. Tidak sedikit dari mereka yang menjadikan budaya Barat sebagai role model dalam kehidupannya, karena mereka memandang itu adalah sebuah seni. Seperti diantaranya seni dalam berpenampilan, musik, arsitektur, dan lain sebagainya. Sebagian dari mereka melakukan itu semua semata-mata hanya untuk memenuhi rasa senangannya saja.

$$
\text { Menurut Maziyaturrodhiyanah }
$$
(2008, hal. 35) seni tidak lepas dari kebudayaan, maka dalam percakapan sehari-hari kebudayaan kerap kali dikaitkan dengan seni dan ilmu. Sejak lahir manusia mempunyai kecenderungan besar terhadap keindahan dan kesenangan. Dengan demikian, keindahan dan kesenangan manusia dapat dipengaruhi gairah hidupnya dan tentu mampu pula membangkitkan semangat kerja untuk berkreasi.

Sedangkan Nanang Rizali (2012) menyebutkan bahwa seni sebagai bahasa universal diharapkan mampu dijadikan sarana untuk mengajak berbuat baik ( $m a$ 'rüf), dan mencegah perbuatan tercela (munkār) serta membangun kehidupan yang berkeadaban dan bermoral. Di samping itu diharapkan dapat mengembangkan dan menumbuhkan perasaan halus, keindahan dan kebenaran menuju keseimbangan 'materialspiritual'. Dengan demikian seni mampu berperan dalam memenuhi kebutuhan manusia baik jasmani maupun rohani, serta dapat memberi kepuasan secara fisik dan psikis.

Namun faktanya, belakang ini marak sekali diberitakan tindakan pornoaksi. Seperti pemberitaan yang dilansir oleh detikcom yakni mengenai penutupan paksa prostitusi Dolly oleh Walikota Surabaya (detikNews, 2014).
Harian Kompas menambahkan ada pula kasus tindakan pelecehan seksual yang melibatkan tujuh siswi SMK di Mataram, Lombok ketujuh siswi ini mendapat perlakuan tidak senonoh yang dilakukan oleh guru agama Islam (Septia, 2015). Ini merupakan segelintir kasus yang diakibatkan terpengaruhnya nilai-nilai negatif budaya Barat.

Djamarah (2004, hlm. 22 \& 29) menyebutkan bahwa keluarga dan pendidikan tidak bisa dipisahkan. Karena selama ini telah diakui bahwa keluarga adalah satu dari Tri Pusat Pendidikan yang menyelenggarakan pendidikan pendidikan secara kodrati. Konteksnya dengan tanggung jawab orang tua dalam pendidikan, maka orang tua adalah pendidik pertama dan utama dalam keluarga. Bagi anak, orang tua adalah model yang harus ditiru dan diteladani. Sebagai model, orang tua seharusnya memberikan contoh yang terbaik bagi anak dalam keluarga. Sikap dan perilaku orang tua harus mencerminkan akhlak yang mulia. Oleh karena itu, Islam mengajarkan kepada orang tua agar selalu mengajarkan sesuatu yang baik-baik saja kepada anak mereka. Dalam salah satu hadits dari Ibn Abbās ra, Bayḥaqi meriwayatkan, Rosulullah saw, bersabda: "Di antara hak orang tua terhadap anaknya adalah mendidiknya dengan budi pekerti yang baik dan memberinya nama yang baik".

Jika melihat fenomena remaja saat ini, tidak sedikit remaja yang menghabiskan waktunya dengan kegiatan-kegitan yang tidak bermanfaat dibandingkan meluangkan waktunya untuk belajar ilmu agama. Sebagaimana Karlina (2008, hlm. 56) dalam penelitiannya menyebutkan minat remaja di salah satu daerah di Jakarta Timur terhadap kegiatan keagamaan adalah biasa-biasa saja (kualifikasi sedang). Hal 
ini ditunjukkan dengan presentase $44.83 \%$ remaja yang tertarik untuk mengikuti kegiatan keagamaan

Adapun hal ini disebabkan oleh tidak adanya faktor-faktor yang menimbulkan minat terhadap kegiatan keagamaan seperti: tidak adanya motivasi, merasa tidak butuh, lingkungan yang tidak mendukung, fasilitas yang tidak memadai, kondisi keluarga, dan teman sepergaulan (Karlina 2008, hlm. 12-13).

Selain itu, kondisi ini diperparah dengan adanya kasus yang baru-baru ini cukup menyita perhatian publik, yakni kasus yang melibatkan seorang da'i kondang (Ustad Hariri). Sebagaimana yang dilansir harian Liputan 6 yang menyebutkan bahwa ustad Hariri memiliki sifat temperamental dan tersulut emosinya (Liputan6, 2014). Ditambah lagi dengan adanya kasus ustad Guntur Bumi (UGB), menurut harian Tempo UGB melakukan tindakan penipuan dan pelecehan seksual yang dalam menjalankan praktik pengobatannya (Atmasari, 2014).

Kasus-kasus diatas tentunya memberikan citra buruk pada dunia dakwah, setelah kesan membosankan dan menjenuhkan karena dakwah yang hanya begitu-begitu saja tanpa ada inovasi atau kesan menarik didalamnya.

Seharusnya dakwah akan berpengaruh terhadap perubahan sikap dan perilaku melalui komunikasi yang dilakukan dengan penuh kesungguhan oleh umat Islam, sehingga pesan-pesan ajaran Islam sampai kepada sasaran dengan tepat. Dan tujuan dari dakwah itu sendiri bisa terwujud untuk mencapai terbentuknya masyarakat Islami, yang pada akhirnya mencapai kebahagiaan di dunia dan akhirat (Munir 2009, hlm. 160).

Dengan demikian solusi yang ditawarkan adalah dakwah yang dilakukan melalui seni Islami, karena sebagaimana yang telah dipaparkan sebelumnya bahwa seni itu sangat disukai sekali oleh berbagai kalangan terutama seni musik. Sehingga dakwah bisa disajikan menjadi sesuatu yang memiliki daya tarik bagi para pendengarnya $\mathrm{Hal}$ ini sejalan dengan Adjie Esa Poetra (2004, hlm. 3) yang menyebutkan bahwa musik dan dakwah merupakan naluri manusia sejak ia dilahirkan, oleh sebab itu beruntunglah bagi mereka yang bisa melakukan hal itu di saat ia dewasa. Sejak dilahirkan, Allah swt telah membekali manusia dua belah otak. Otak kiri adalah bagian otak yang berhubungan dengan fungsi berfikir, sedangkan orak kanan berhubungan dengan fungsi intuisi.

Seperti yang telah diketahui bersama bahwa Islam sebagai agama yang sempurna tentunya mengandung segala aspek yang dibutuhkan oleh manusia termasuk didalamnya seni musik Islami yang diharapkan bisa memberikan sumbangsih positif bagi penanaman nilainilai agama pada setiap individu. Ini bisa menjadi alternatif bagi umat muslim agar bisa mendapatkan syiar-syiar Islam yang tentunya tanpa menghilangkan esensi majelis ilmu sebagai tempat untuk menuntut ilmu.

\section{METODE}

Pendekatan yang digunakan dalam penelitian ini adalah pendekatan kualitatif. Melalui pendekatan kualitatif diperoleh pemahaman dan penafsiran yang mendalam mengenai makna, kenyataan, dan fakta yang relevan (Basrowi \& Suwandi, 2008, hlm. 187). Dalam hal ini Moleong (dalam Basrowi \& Suwandi, 2008, hlm. 187), mengemukakan bahwa penelitian kualitatif antara lain bersifat deskriptif, data yang dikumpulkan lebih banyak berupa kata-kata atau gambar daripada angka-angkat.

Adapun tujuan penelitian deskriptif adalah untuk membuat pecandraan secara sistematis, faktual, dan 
akurat mengenai fakta-fakta dan sifatsifat populasi atau daerah tertentu. Secara harfiah, penelitian deskriptif adalah penelitian yang bermaksud untuk membuat pencandraan (deskripsi) mengenai situasi-situasi atau kejadiankejadian (Suryabrata, 2012, hlm 75).

Maka dari itu penelitian ini bertujuan untuk mendeskripsikan secara alami tanpa adanya manipulasi data lapangan terhadap implementasi dakwah Islam melalui seni musik Islami yang dilakukan oleh grup nasyid EdCoustic. Adapun subjek pada penelitian ini adalah personil EdCoustic, manajemen EdCoustic dan EdFriends.

Teknik pengumpulan data yang dilakukan peneliti melalui observasi, wawancara, studi dokumentasi dan triangulasi. Setelah itu peneliti melakukan member check. Menurut Sugiyono (2013, hlm. 375) member check adalah proses pengecekan data yang diperoleh peneliti kepada pemberi data. Berikut pemaparan ketiga teknik pengumpulan data yang peneliti gunakan.

Setelah data terkumpul, peneliti melakukan analisis data. Miles \& Huberman (dalam Gunawan, 2013, hlm. 210) mengemukakan tiga tahapan yang harus dikerjakan dalam menganalisis data penelitian kualitatif, yaitu (1) reduksi data (data reduction), paparan data (data display), dan (3) penarikan kesimpulan dan verifikasi (conclusion drawing/verifying). Analisis data kualitatif dilakukan secara bersamaan dengan proses pengumpulan data berlangsung, artinya kegiatan-kegiatan tersebut dilakukan juga selama dan sesudah pengumpulan data.

\section{HASIL DAN PEMBAHASAN}

\section{Profil EdCoustic}

EdCoustic adalahgrupmusik religi

atau nasyid di Indonesia yang berasal dari Bandung yang mengusung konsep musik humanis religius. Dibentuk pada 25 Mei 2002, dengan dua orang anggota yakni Aden (Vokalis) dan Eggie (Gitaris) (W.EdC) \& (D.PE).

Pada mulanya Aden dan Eggie mengikuti sebuah festival nasyid, mereka mendaftarkan grupnya dengan nama MIIY (Muhammad Isa Ibrahim Yusuf). Hasilnya mereka masuk daftar grup yang diberikan kesempatan untuk rekaman. Lagu perdana mereka "Remaja Peduli" bersanding dengan lagu lain yang ada di album kompilasi Bandung Nasheed Exhibition 2002. Tahun 2004 pihak Yess Studio menghubungi mereka untuk menjalin kontrak rekaman. Dan lahirlah album Masa Muda tahun 2004, dengan berganti nama menjadi EdCoustic. Hingga saat ini EdCoustic sudah memiliki empat buah album yang terbilang cukup laris di pasaran. (W.EdC) \& (D.PE).

2. Perencanaan Dakwah Islam EdCoustic Melalui Seni Musik Islami Menurut Wahidin Saputra (2011, hlm. 290) suatu perencanaan hendaknya memenuhi kriteria sebagai berikut:

a. Meyakini bahwa apa yang akan dilakukan adalah baik, dan sebagai landasannya adalah al-Quran dan as-Sunnah.

Dalam kegiatan dakwahnya, EdCoustic menyatakan bahwa mereka menjadikan kemampuan dan keahlian yang dimiliki sebagai landasan dalam melakukan dakwahnya di bidang musik dan lagu. Ia juga mengatakan bahwa segala aktivitas positif yang dilakukan oleh umat Islam tidak akan pernah lepas dari yang namanya dakwah, termasuk di dalamnya dakwah yang dikemas melalui seni musik (W.EdC).

Pernyataan di atas sejalan dengan pendapat yang dikemukakan oleh Muhammad Nasirir yang mengemukakan bahwa dakwah mengandung arti kewajiban yang menjadi tanggung jawab 
seorang muslim dalam amar ma'rüf nahi mungkar. Kemudian Prof. Dr. Hamka menyebutkan bahwa dakwah adalah seruan panggilan untuk menganut suatu pendirian yang pada dasarnya berkonotasi positif dengan substansi terletak pada aktivitas yang memerintahkan amar ma'rüf nahi mungkar (Saputra, 2011, hlm. 2).

Merujuk pada pernyataan yang dilontarkan oleh narasumber dan pernyataan Muhammad Nasiir dan Hamka di atas, maka peneliti menyimpulkan meskipun narasumber tidak secara eksplisit menyebutkan al-Quran dan Sunnah sebagai landasannya, mereka menyebutkan bahwa segala aktivitas umat Islam tidak lepas dari yang namanya dakwah. Hal ini mengindikasikan bahwa narasumber menjalankan aktivitas dakwahnya melalui musik berlandaskan al-Quran dan Sunnah. Hal ini diperkuat lagi oleh buktibukti nyata mengenai konten-konten yang dijadikan materi dakwah oleh EdCoustic yakni lagu-lagunya yang tidak menyimpang dari ajaran Islam.

Seperti yang dijelaskan oleh Bambang Saiful Ma'arif (2010, hlm. 178) yang menyebutkan beberapa kriteria suatu lagu dapat dikatakan sebagai 'lagu yang bernafaskan agama,' adalah sebagai berikut: (1) liriknya membawa kepada pengagungan Allah Rabb yang Maha Esa, (2) unsur musikalitasnya tidak cadas sehingga dapat membina jiwa secara baik. Jiwa yang disentuh oleh jenis musik (religi), terbentuk untuk tetap bersikap baik, santun dan bijak kepada sesama manusia, serta peduli pada alam sehingga tidak membuat keonaran dan kerusakan, (3) membawa pada makna-makna akan kesejatian kehidupan. Kita ini berasal dari mana, hendak ke mana, dan jalannya bagaimana. Hidup penuh dengan makna yang dapat dipancarkan melalui musik, (4) menghindarkan hal-hal yang sahūn atau lahūn (lupa diri) karena terperdaya oleh rayuan lagu-lagu yang didengarnya, baik lirik, jenis musiknya, maupun tampilannya dipanggung, (5) menjadikan manusia merenungi akan alam dan budayanya sebagai pemberian Allah SWT. Kriteria tersebut dapat terus disempurnakan dan dikontekstualisasikan secara fleksibel.

Adjie Esa Poetra menyebutkan bahwa dalam membentuk grup nasyid perlu penataan atau manajemen yang tepat. Pertama kali yang perlu diperhatikan adalah masalah visi. Di dalamnya termasuk pantangan tentang nasyid itu sendiri atau paling tidak semua yang tergabung didalamnya perlu menyadari betul bahwa nasyid merupakan seni musik dakwah. Semuanya itu perlu ditindak lanjuti dengan kesalehan para anggotanya (2004, hlm. 123).

\section{b. Pastikan bahwa aktivitas yang akan dilaksanakan memiliki manfaat yang baik. \\ Melalui tujuannya 'Inspiring}

People' EdCoustic berharap para pendengarnya bisa mengambil manfaat dari dakwah yang dilakukannya. Lagulagu yang dibawakan oleh EdCoustic sebagian besar merupakan pengalaman spiritual yang dialami personilnya. Maka dari itu EdCoustic berharap ketika para pendengarnya mendengarkan lagu EdCoustic, lagu tersebut bisa semakin mengingatkan mereka kepada Allah SWT (W.EdC).

Syekh Ali Mahfudz mengartikan bahwa dakwah adalah mengajak manusia untuk mengerjakan kebaikan dan mengikuti petunjuk, menyuruh mereka berbuat baik dan melarang mereka dari perbuatan jelek agar mereka mendapat kebahagiaan di dunia dan akhirat (Munir M. , 2009, hlm. 7).

\section{c. Berdasarkan ilmu pengetahuan.}

Menurut pemaparan kang Eggie selaku narasumber, dalam menjalankan kegiatan dakwah melalui musik, pelaku 
dakwah tentunya harus pandai menguasai ilmu tentang musik. Selain ilmu musik, ilmu lainnya pun ada beberapa ilmu yang bisa menunjang, seperti ilmu manajemen dan marketing. Tidak hanya ilmu-ilmu itu saja, mengingat musik yang mereka bawakan ditujukan untuk dakwah maka ilmu agama pun tidak kalah pentingnya. Melalui kajian-kajian keislaman, pengalaman-pengalaman spiritual yang dirasakan, dan pengajian rutin yang sering dilakukan setiap minggunya. Itu semua yang menjadi modal keilmuan yang EdCoustic miliki dalam dakwahnya. Ia pun mengungkapkan bahwa ia berdakwah tidak layaknya seperti para da'i pada umumnya yang mempelajari naḥwu dan șorof. Karena dakwah yang dilakukan oleh EdCoustic berbeda dari hal itu. (W.EdC).

Sedangkan dalam hal ini Samsul

Munir Amin (2009, hlm. 79-85) menyebutkan terdapat beberapa kompetensi yang harus dimiliki oleh da'i yakni seperti: kemampuan berkomunikasi, kemampuan penguasaan diri, kemampuan pengetahuan psikologi, kemampuan kependidikan, kemampuan di bidang pengetahuan umum, kemampuan di bidang al-Quran, kemampuan pengetahuan di bidang ilmu hadis, dan kemampuan di bidang ilmu agama secara integral.

\section{d. Dipikirkan dan dianalisis prosesnya serta kelanjutan dari aktivitas yang akan dilaksanakan.}

Saat ini kang Eggie sedang fokus untuk mengembangkan Musik Positif, sekaligus menjabat sebagai owner-nya. Musik Positif ini dibentuk sebagai wujud kepeduliannya terhadap para pelaku nasyid di Indonesia, sekaligus sebagai wadah bagi para munsyid untuk berkarya. Musik Positif bekerja sama dengan Alfa Records, yaitu label musik yang sudah memiliki nama di belantika musik Indonesia dan menaungi artis-artis ternama Indonesia (W.EdC).
Melihat usaha yang dilakukan EdCoustic dalam mengembangkan dakwahnya, peneliti menilai bahwa dengan dibentuknya Musik Positif ini merupakan gebrakan baru dalam pergerakan nasyid di Indonesia. Dengan adanya Musik Positif ini diharapkan bisa menjadi wadah bagi para munsyid untuk melestarikan dakwahnya melalui syair. Karena memang karier nasyid di Indonesia setiap waktunya mengalami pergerakan yang baik. Hal itu akan peneliti kaji pada pembahasan selanjutnya.

\section{e. Perkirakan dan perhitungkan masa depan. \\ Tidak banyak kata yang} dilontarkan oleh narasumber. EdCoustic hanya menegaskan bahwasannya masa depan nasyid 'insya Allah' cemerlang. Hal ini EdCoustic buktikan dengan tindakan nyata, melalui launching album baru yang akan diadakan pada tahun 2017 atau 2018 mendatang (W.EdC).

Menurut Adjie Esa Poetra (2004, hlm. 117) nasyid bukan lagi tengah menjadi musik popular melainkan telah menjadi musik rakyat. Di usianya yang baru berkembang di Indonesia 5-6 tahun boleh disebut sebagai luar biasa apabila kenyataannya nasyid kemudian menjadi seperti sekarang ini. Nasyid saat ini bukan lagi model musik yang didominasi kalangan santri di perguruan tinggi, melainkan juga dikalangan anak-anak sekolahan, bapak-bapak, ibu-ibu, termasuk dicintai kalangan eksekutif.

Berkaca pada perkembangan nasyid di Indonesia dari generasi ke generasi, peneliti berkesimpulan bahwasannya nasyid akan memiliki umur panjang dalam kiprahnya sebagai wujud dakwah Islam. Terlebih lagi khususnya nasyid EdCoustic yang sudah melanglang buana di jagad nasyid Indonesia bahkan sampai luar Indonesia dan memiliki banyak project sebagai usaha pelebaran sayapnya dalam dunia dakwah 
diprediksikan akan mampu mempertahankan eksistensinya dalam jangka waktu yang cukup lama.

\section{f. Menetapkan tindakan-tindakan dakwah serta penjadwalan waktu, lokasi, biaya, materi, metode dan yang lainnya.}

1) Penjadwalan waktu, lokasi dan biaya. Penetapan waktu dan lokasi disepakati diantara pihak pengundang dan EdCoustic. Adapun dana yang dibutuhkan oleh EdCoustic ditanggung oleh pihak pengundang. Baik itu untuk area Jawa, area luar Jawa dan area Internasional yang terbagi kepada tiga wilayah, yakni: Asia Tenggara, Asia, Afrika, Eropa, Amerika dan Australia. Untuk wilayah Asia Tenggara (W.EdC) \& (D.AR).

\section{2) Materi Dakwah.}

Karena EdCoustic bergerak dalam dakwah melalui seni musik Islami, maka pesan-pesan dakwah yang hendak disampaikannya pun berbentuk syair atau lagu. Banyak sekali nilai-nilai Islami yang terkandung dalam setiap lagu EdCoustic (W.EdC) \& (D.LL).

Sebagaimana pendapat Samsul Munir Amin (2009, hlm. 89-92) yang menjelaskan bahwa secara konseptual pada dasarnya materi dakwah Islam tergantung pada tujuan dakwah yang hendak dicapai. Namun, secara global materi dakwah dapat diklasifikasikan menjadi tiga pokok, yaitu: masalah keimanan (aqidah), masalah keislaman (syariat) dan masalah budi pekerti (akhlaqul karimah).

\section{3) Metode dakwah}

Sebelum memasuki medan dakwah tentunya perlu perencanaan yang matang, salah satu aspek yang menjadi perhatian EdCoustic adalah bagaimana cara menarik perhatian pendengarnya. Kang Eggie menuturkan bahwa tidak ada metode khusus dalam dakwah yang dilakukan EdCoustic, ia menegaskan bahwa kekuatan dakwah dalam musik terletak pada lagu yang dibawakannya. Adapun lagu yang dibawakan EdCoustic sebagian besarnya berasal dari kisah nyata para personilnya. Sehingga diharapkan para pendengarnya bisa mengambil hikmah melalui lagu-lagunya (W.EdC).

Dalam hal ini Samsul Munir Amin (2009, hlm. 101-105) menjelaskan apabila ditinjau dari sudut pandang yang lain, metode dakwah dapat dilakukan pada berbagai metode yang lazim dilakukan dalam pelaksanaan dakwah. Metode-metode tersebut adalah sebagai berikut: metode ceramah, metode tanya jawab, metode diskusi, metode propaganda, metode keteladanan, metode drama dan metode silaturahim (Home Visit).

Adapun jika menurut Wahidin Saputra (2011, hlm. 244-253) metode dakwah itu meliputi tiga cakupan, yaitu: metode bi al-hikmah, metode almaw'idza al-hasanaћ, dan metode almujadalaћ.

Berdasarkan pada pemaparan teori di atas, maka dapat disimpulkan bahwa jika merujuk pada teori Samsul Munir Amin maka metode dakwah yang dilakukan oleh EdCoustic adalah metode propaganda. Sedangkan jika jika merujuk pada teori Wahidin Saputra maka metode dakwah yang dilakukan oleh EdCoustic adalah metode bi al-Hikmaћ.

4) Media dakwah

Selain itu untuk menunjang dakwah EdCoustic perlu juga sarana dan prasarana yang harus dipersiapkan. Dalam dakwahnya EdCoustic menyiapkan perangkat media sosial, alat musik (gitar) dan perlengkapan pakaian yang menunjang penampilannya, recorder dan kantor (W.EdC).

Menurut Samsul Munir Amin (2009, hlm 116-125) terdapat beberapa media yang dapat digunakan dalam dakwah, yakni diantaranya: media visual, 
media audio, media audio visual dan media cetak.

Dalam kemajuan ilmu dan teknologi, muncul pula media baru yang dikenal sebagai media interaktif melalui komputer yang disebut dengan nama internet (international networking). Internet adalah jaringan komputer di seluruh dunia, dan dapat disebut sebagai kolaborasi teknis antara komputer, telepon dan televisi (Arifin, 2011, hlm. 89).

Merujuk pada pemaparan di atas, maka media yang biasa digunakan oleh EdCoustic dalam dakwahnya adalah media audio, media audio visual dan internet. Adapun media audio ini biasa dilakukan melalui lagu-lagu EdCoustic dalam bentuk CD MP3 atau melalui radio. Sedangkan media audio visual biasa dilakukan melalui penampilanpenampilan EdCoustic secara langsung di atas panggung atau melalui televisi. Adapun melalui media internet dakwah EdCoustic biasa dilakukan melalui Twitter, Facebook, YouTube dan Instagram.

3. Pengorganisasian Dakwah Islam EdCoustic Melalui Seni Musik Islami Menurut Samsul Munir Amin (2009, hlm. 232-233) dalam organisasi dakwah terdapat empat langkah yang harus ditempuh, yaitu:

a) Membagi-bagi pekerjaan atau tindakan dakwah yang sudah ditetapkan dalam perencanaan.

Manajemen EdCoustic dibantu oleh tiga divisi. Ketiga divisi yang dimaksud adalah divisi merchandising, social media dan road manager. Divisi merchandising berkewajiban untuk mengatur keluar masuknya merchandise dan melayani setiap pemesanan $\mathrm{CD}$, kaos dan sebagainya. Divisi media sosial memiliki tugas untuk mengelola akunakun sosial media sosial seperti facebook dan twitter. Divisi road manager bertugas untuk mengatur jadwal tampil EdCoustic. Sedangkan untuk pembuatan lagu ditugaskan kepada kang Aden dan kang Eggie lebih kepada arransement musiknya. Adapun tugas kang Eggie lainnya adalah mengelola marketing bersama tim marketing. Kemudian tugas lainnya adalah mempertahankan brand (W.EdC) \& (W.M.EdC).

b) Menetapkan dan mengelompokkan orang atau para da'i dalam melaksanakan tugasnya.

Adapun setiap divisi dalam manajemen EdCoustic dikelola oleh satu orang. Divisi merchandising dikelola oleh teh Ita, kemudian divisi social media dikelola oleh teh Cinta Komala dan divisi road manager dikelola oleh kang Taufan dan bagian umum manajemen EdCoustic dipercayakan kepada kang Iqbal. Pembagian setiap divisi ini dilakukan oleh kang Eggie sendiri dan hanya berdasarkan ketepatan dan kecocokan setiap individunya (W.EdC) \& (W.M.EdC).

c) Menetapkan tempat atau lingkungan di mana aktivitas dakwah itu akan dikerjakan.

Berbicara mengenai tempat dan lingkungan yang akan dijadikan medan dakwah EdCoustic, maka hal itu sudah tercantum dalam artist riders yang mereka miliki. Dalam artist riders tersebut tertera kategori usia yang akan menjadi sasaran dakwah EdCoustic, yakni diantaranya: anak-anak, remaja, mahasiswa, orang tua dan umum. Selain itu di dalam artist riders dicantumkan pula jenis acaranya, seperti: komersial, sosial, keagamaan, corporate dan resepsi (D.AR).

d) Menetapkan jalinan kerjasama antara para da'i sebagai suatu

Untuk menguatkan jalinan internal EdCoustic biasanya kembali menguatkan visi dalam dakwahnya. Kang Iqbal selaku perwakilan manajemen EdCoustic menambahkan bahwa dengan memiliki sikap saling terbuka, 
kekeluargaan, komunikasi dan tanggung jawab mampu menjaga hubungan baik antar manajemen EdCoustic (W.EdC), (W.M.EdC) \& (D.LL).

Agar dakwah EdCoustic mampu bertahan dalam waktu yang lama, maka dibutuhkan kekompakan didalamnya. Begitu pun dengan manajemen EdCoustic yang harus menjalin hubungan baik. Hal ini disadari oleh kang Eggie selaku personil EdCoustic. EdCoustic selalu mengadakan silaturahmi dengan sesama munsyid. Terkadang acara silaturahminya dikemas melalui tampil bernyanyi bersama. Silaturahmi yang dilakukan EdCoustic ini terlihat ketika acara lomba karaoke EdCoustic, acara Civics Islamic Fair di UPI, dan acara Pagelaran Cimahi Untuk Palestina. Selain itu silaturahmi juga dilakukan melalui komunitas nasyid Indonesia, melalui Musik Positif (W.EdC), (W.M.EdC) \& (O2.EdC).

\section{Pelaksanaan Dakwah Islam EdCoustic Melalui Seni Musik Islami Menurut Wahidin Saputra (2011,} hlm. 299) aspek pelaksanaan merupakan suatu hal yang harus diperhatikan oleh pelaku dakwah dalam menyampaikan dan merealisasikan kegiatan-kegiatan dakwah yang telah direncanakan, diantaranya: (a) Ar-Ruhiyah (Spiritual), (b) Al-Fikriyah (Pemikiran), (c) Al-Maliya (Material), (d) Al-Maidaniyah (Penguasaan Lapangan), (e) Al-Harakiyah (Gerakan Dakwah).

\section{a. Ar-Ruhiyah (Spiritual)}

Sudah menjadi kebiasaan bagi para da'i untuk dapat meningkatkan ketahanan ruhiyahnya, sehingga ia tidak lemah dalam mengemban tugas mulia, bila perlu setiap pendakwah memiliki program personal dalam menjaga ketahanan ruhiyah, seperti merutinkan diri untuk shalat berjamaah di masjid, puasa sunnah, tahajud, sedekah atau aktivitas lainnya yang berakibat pada kesehatan ruhaniyahnya (Saputra, 2011, hlm. 299).

Selain memberikan nilai-nilai spiritual kepada para pendengarnya, EdCoustic pun senantiasa meningkatkan keimanannya. Adapun usaha yang dilakukannya adalah pengajian rutin mingguan, membaca buku-buku Islami dan ia selalu belajar dari pengalaman yang ia alami yang kemudian ia bagikan kepada para pendengarnya. Selanjutnya pada acara Civics Islamic Fair aspek ArRuhiyah EdCoustic ini terlihat dari ajakan personilnya untuk mengajak para peserta dan panitia sholat berjamaah di masjid alFurqōn selepas acara berakhir. Terakhir pada acara Pagelaran Cimahi Untuk Palestina, acara ini merupakan konser amal yang dilakukan oleh Komite Nasional Rakyat Palestina Kota Cimahi. Pada acara ini EdCoustic tampil dan ikut memberikan sumbangan dana. Melalui penjualan $\mathrm{CD}$ yang sebagian hasil penjualannya akan didonasikan untuk saudara muslim Palestina (W.EdC), (O1.UPI) \& (O1.PUS).

\section{b. Al-Fikriyah (Pemikiran)}

Telah banyak paparan al-Quran atau hadis yang menyuruh untuk memberdayakan kemampuan berpikir dengan melakukan pengamatan dan pengkajian. Sehingga pemikiran da'i senantiasa dalam pencerahan bahkan ia selalu dapat mencari solusi yang pas. Bila demikian halnya, pemikiran da'i senantiasa berkembang dan menjadi pintu gerbang kemajuan intelektual (Saputra, 2011, hlm. 299).

Sebagaimana yang dikatakan di awal bahwa kekuatan dan pesan dakwah EdCoustic terletak pada lagu yang dibawakannya. Secara keseluruhan pada serangkaian pelaksanaan dakwah EdCoustic di Lomba Karaoke EdCoustic, Civics Islamic Fair dan Pagelaran Cimahi Untuk Palestina, maka lagu-lagu yang dibawakannya adalah sebagai berikut: Sholatku, Sebiru Hari Ini, Kioku, Satu 
Cinta Berbagai Bahagia, Sendiri Menyepi, Muhasabah Cinta, Pertengkaran Kecil, Kau Ditakdirkan Untukku, Jalan Masih Panjang, Aku Ingin MencintaiMu, Berubah, Dipersimpangan Aku Berdiri, dan Find The Way. Lagu-lagu ini mengandung nilai-nilai aqidah, ibadah dan akhlak. Melalui lagu-lagu itu EdCoustic menyampaikan pemikirannya.

\section{c. Al-Maliyaћ (Material)}

Dakwah juga dipengaruhi oleh kekuatan material. Tidak terkecuali para pengembannya. Karena itu setiap da'i harus memiliki kemampuan entrepreneurship agar tidak menjadi beban orang lain. Da'i harus memiliki kemampuan mencari penghidupan bagi dirinya (Saputra, 2011, hlm. 299).

Seperti yang telah dipaparkan sebelumnya bahwa disamping disibukkan dengan nasyidnya, kang Eggie memiliki usaha lain yakni bisnis katering. Usaha katering yang ia jalani dengan bantuan orang lain untuk memudahkan pengelolaannya (W.EdC).

\section{d. Al-Maydaniyah \\ Lapangan)}

(Penguasaan

Penguasaan lapangan juga hal yang sangat penting bagi perkembangan pergerakan dakwah. Seorang da'i harus memahami medan yang dihadapinya dengan cepat, penguasaan lapangan yang cepat dapat memperoleh taktik dan strategi yang tepat untuk berdakwah (Saputra, 2011, hlm. 299).

Sebagaimana yang telah diutarakan sebelumnya, dakwah itu bersifat luas tidak hanya ceramah diatas mimbar saja. Melalui musik pun merupakan strategi yang bisa digunakan untuk melangsungkan suatu dakwah dan kekuatannya terletak pada musik dan isi lagu tersebut. Dalam setiap penampilannya, EdCoustic selalu memperhatikan secara detail siapa objek dakwahnya, pakaian apa yang harus dikenakan. Pada intinya EdCoustic selalu berusaha tampil sesuai dengan pendengarnya (W.EdC).

Berdasarkan hal tersebut, peneliti mengutip perkataan Samsul Munir Amin (2009, hlm. 250) yang menyebutkan bahwa berbagai kesenian, sebenarnya bisa dimanfaatkan untuk menyebarkan pesan-pesan dakwah Islam. Musik kasidah, musik dangdut, sandiwara, wayang kulit, teater, sastra melalui puisi, novel, bahkan film, sinetron (keagamaan) adalah seni yang bisa digunakan sebagai media dakwah. Seni ini lebih berifat populer, merakyat, dan kondisional. Apa yang ada di masyarakat pada waktu itu dapat diangkat kepermukaan bersama pesan dakwah Islamiyyah.

\section{e. Al-Harakiyah (Gerakan Dakwah)}

Penguasaan harakiyah perlu diperhatikan, sehingga pendakwah dapat mengikuti laju dakwahnya. pemahaman terhadap gerakan dakwah yang tepat dapat pelahirkan sikap da'i yang mengerti benar tentang sikap apa yang harus dilakukan untuk kepentingan dakwah. Pergerakan dalam dakwah terdiri dari langkah-langkah berikut: pemberian motivasi, pembimbingan, perjalinan hubungan, penyelenggaraan komunikasi, dan pengembangan atau peningkatan pelaksanaan (Saputra, 2011, hlm. 299).

Perlu diketahui bahwasannya dakwah EdCoustic tidak berjalan seorang diri, melainkan terdapat pula peranan manajemen didalamnya. Meskipun tidak ada istilah ketua dalam manajemen EdCoustic, pergerakan manajemen EdCoustic dimotori oleh kang Eggie. Biasanya setiap seminggu sekali kang Eggie selalu mengadakan pertemuan rutin dengan tim manajemen. Adapun yang menjadi agenda pertemuan itu biasanya membahas tentang kemajuan EdCoustic dan manajemennya. Kegiatan seperti ini dirasa sangat penting sekali khususnya dalam manajemen EdCoustic, karena manajemen EdCoustic bekerja 
secara terpisah. Hal ini disebabkan anggotanya memiliki kesibukan lain diluar aktivitasnya dalam manajemen EdCoustic. Tetapi dengan kecanggihan teknologi, komunikasi setiap anggotanya masih berjalan lancar melalui jejaring sosial (W.M.EdC).

5. Keberhasilan Dakwah Islam Melalui Seni Musik Islami

Berdasarkan hasil temuan di lapangan, keberhasilan dakwah EdCoustic bergantung pada tercapainya visi, misi serta motto yang diembannya, diterimanya EdCoustic di masyarakat, respon positif pendengarnya, dan banyaknya prestasi yang diraih.

EdCoustic memiliki ekspektasi tersendiri dalam dakwahnya. Sebagaimana yang diutarakan oleh kang Eggie bahwa ekspektasi terbesarnya adalah ketika EdCoustic sedang tampil, para penontonnya ikut bernyanyi. Kang Eggie menyebut hal itu adalah suatu kenikatan tersendiri bagi pelaku nasyid. Hal ini jelas sekali terlihat ketika EdCoustic tampil di acara Civics Islamic Fair dan Pagelaran Cimahi Untuk Palestina. Euforia kegembiraan penonton sangat terasa di dalamnya. Hal ini ditunjukkan dengan aksi sebagian penonton yang beranjak dari tempat duduknya hanya untuk menikmati penampilan dan bernyanyi bersama EdCoustic secara lebih dekat.

Selain itu tak kalah pentingnya adalah adanya perubahan positif yang dirasakan para pendengarnya. Kang Eggie menyebutkan, bahwa ada beberapa pendengarnya memiliki pengalaman yang luar biasa akibat dari dakwahnya EdCoustic. Salah satunya adalah pengalaman yang dialami ibu Tatin Sardjiman. Selama tujuh tahun lamanya ia menderita kanker payudara. Saat mendengar lagu Muhasabah Cinta milik EdCoustic, ia kembali mendapatkan semangat untuk sembuh. Lagu itu ia jadikan lagu wajib untuk diperdengarkan setiap hari dan kini kondisinya berangsur pulih. Masih banyak lagi pengalamanpengalaman yang dialami oleh para pendengarnya, seperti pengalaman pendengarnya asal dari Solo yang kini ia memeluk agama Islam (W.EdC), (W.TSa), (O1.UPI), (O1.CMH) \& (D.LL).

Sejauh ini respon pendengar terhadap EdCoustic terbilang cukup baik. Hal ini ditandai dengan banyaknya reward yang diterima dari penggemarnya. Salah respon yang datangnya dari teh Ajeng, ia menyebutkan bahwa EdCoustic mampu menghadirkan lagu-lagu yang beda dalam dakwahnya. Berbeda dengan lagu-lagu Islami lainnya, lagu EdCoustic itu lebih mudah dipahami dan memiliki cerita didalamnya (W.EdC) \& (W.AL).

Ibu Tatin menyebutkan bahwa dakwah EdCoustic sudah berhasil, buktinya penyakitnya berangsur pulih adalah lagu EdCoustic. Kemudian kang Yayan menyebutkan hal yang sama dengan alasan, EdCoustic mampu memberikan inspirasi dan motivasi kepadanya agar terus berkarya. Selanjutnya teh Cinta menyebutkan bahwa tujuan EdCoustic yang Inspiring People itu memang benar-benar telah memberikan inspirasi padanya. Hampir semua rekan-rekan di sekolahnya hafal beberapa lagu milik EdCoustic. Kang Tatang menambahkan EdCoustic tidak hanya berhasil di Indonesia saja, bahkan berhasil hingga keluar negeri seperti Malaysia dan negara-negara lainnya. Terakhir menurut pendapat kang Ahmad, EdCoustic berhasil membuat hidup saya lebih baik dan ada perubahan dari hari ke harinya (W.TSa), (W.YH), (W.CK), (W.TSu) \& (W.MM).

Hingga detik ini EdCoustic banyak meraih prestasi dalam dunia dakwahnya melalui nasyid. Penghargaan 
Live Time Achievment, Grup Terbaik, Grup Terfavorit, Grup Romantic Duo dari Indonesian Nasyid Awards. Selain itu penjualan album EdCoustic menjadi prestasi tersendiri baginya. Album pertama terjual sebanyak 30.000 keping, album kedua terjual sebanyak 10.000 keping, album ketiga terjual sebanyak 20.000 keping dan album keempat baru terjual sebanyak 1300 keping (W.EdC).

Kang Eggie menambahkan sebenarnya ada tolak ukur keberhasilan EdCoustic, yakni diantaranya: Pertama, pendengarnya terinspirasi dan mengalami perubahan kearah yang lebih baik. Kedua, pendengarnya hafal akan semua lagunya, dan ketiga karya mereka diterima dan dihargai dengan membelinya secara legal (W.EdC).

\section{KESIMPULAN}

Hasil penelitian di lapangan yang
menyebutkan bahwa kegiatan
perencanaan EdCoustic dalam
implementasi dakwahnya sudah baik dan
memenuhi standar yang semestinya.
Standar perencanaan dakwah yang ideal,
yakni (1) Adanya standar operasional
prosedur, visi, misi dan tujuan dakwah
yang hendak dicapainya tidak
bertentangan dengan ajaran Islam. (2)
Aktivitas dakwah melalui syair lagunya memiliki nilai manfaat. (3) Ilmu yang mereka miliki untuk terjun ke dalam dunia dakwah melalui musik sudah cukup mumpuni. Ilmu yang dimaksud adalah ilmu musik, ilmu agama dan ilmu marketing. (4 \& 5) Memikirkan dan menganalisis jangka panjang kariernya dalam dunia dakwah melalui musik, alhasil kini EdCoustic membentuk komunitas Musik Positif untuk terus berkarya dalam mengembangkan dunia dakwah melalui lagu. (6) Membuat penjadwalan waktu, lokasi, biaya, materi dan metode dalam dakwahnya. Untuk waktu, lokasi dan biaya sudah mereka rumuskan dalam bentuk artist riders, sedangkan materi mereka buat dalam bentuk lagu yang berisikan nilai-nilai aqidah, ibadah dan akhlak, sedangkan metode dakwah yang mereka gunakan adalah metode propaganda, yakni metode yang digunakan dalam bentuk hiburan pertunjukkan seni serta metode $b i$ alHikmaћ dengan menyampaikan hikmahhikmah melalui lagu-lagunya.

Sedangkan dalam kegiatan pengorganisasian EdCoustic pun sudah terbilang baik dan memenuhi standar ideal perorganisasian dakwah. Hal ini bisa terlihat dari: (1) Adanya tiga divisi dalam manajemen EdCoustic yakni, divisi merchandising, social media dan road manager. Ketiganya memiliki tugas yang berbeda-beda. Adapun pembagian tugas pada personilnya adalah kang Eggie hanya mengelola aset lagu serta mengelola marketing bersama tim marketing dan mempertahankan brand. Sementara kang Aden hanya berfokus pada penciptaan lagu-lagu EdCoustic dan kang Eggie lebih kepada arransement musiknya. (2) Setiap divisi dalam manajemen EdCoustic dikelola oleh satu orang. Divisi merchandising dikelola oleh teh Ita, kemudian divisi social media dikelola oleh teh Cinta Komala dan divisi road manager dikelola oleh kang Taufan dan bagian umum manajemen EdCoustic dipercayakan kepada kang Iqbal. (3) Menetapkan tempat atau lingkungan aktivitas dakwah itu akan dikerjakan. Tempat dan lingkungan yang dimaksud adalah sasaran atau objek dakwah. Hal itu sudah tercantum dalam artist riders yang mereka miliki. (4) Menetapkan jalinan kerjasama antara para da'i sebagai suatu kesatuan kelompok kerja. Hal ini sudah terlihat dari banyaknya bentuk kerjasama yang EdCoustic lakukan, baik itu acaraacara yang dilakukan bersama ataupun pembentukan Musik Positif yang telah disebutkan sebelumnya.

Selanjutnya pada tataran pelaksanaan dakwah EdCoustic sudah 
memenuhi standar pelaksanaan dakwah yang terdiri dari: (a) Ar-Ruhiyah (Spiritual), EdCoustic senantiasa melaksanakan sholat lima waktu, amalan sunnah dan bersedekah, (b) Al-Fikriya (Pemikiran), melalui lagu-lagunya EdCoustic memberikan sumbangsih pemikiran dalam dakwahnya, (c) AlMaliyah (Material), selain fokus dalam dakwah melalui lagu, sebagai bentuk kemandiriannya kang Eggie EdCoustic pun memiliki usaha tersendiri yang bergerak dibidang katering. (d) $\mathrm{Al}$ Madaniya (Penguasaan Lapangan), EdCoustic senantiasa mengkaji medan dakwah yang hendak mereka jadikan sasaran atau objek dakwahnya (e) AlHarakiyah (Gerakan Dakwah), dalam implementasinya EdCoustic pun didukung oleh tim manajemen yang menjadi motor pergerakan dakwah yang dilakukan oleh EdCoustic. Itu semua dikepalai oleh kang Eggie yang merangkap juga sebagai personilnya. Pada simpulan mengenai keberhasilan dakwah EdCoustic, peneliti menyimpulkan bahwa dakwah yang dilakukan oleh EdCoustic sudah bisa dikatakan berhasil. Hal ini ditunjukkan dengan banyaknya respon positif yang datang dari para pendengarnya baik di dalam maupun luar negeri, ada pula perubahan positif yang dirasakan oleh pendengarnya sebagai akibat dari dakwah yang dilakukan EdCoustic, prestasi dan penghargaan yang diraih selama EdCoustic berkiprah dalam dakwahnya, yakni: Penghargaan Live Time Achievment, Grup Terbaik, Grup Terfavorit, Grup Romantic Duo dari Indonesian Nasyid Awards. Itu semua sudah mempu menjawab visi, misi dan tujuan yang EdCoustic canangkan sejak awal pergerakannya dalam dunia dakwah melalui seni musik Islami.

\section{DAFTAR PUSTAKA}

Arifin, A. (2011). Dakwah Kontemporer. Yogyakarta: Graha Ilmu.

Atmasari, R. (2014, Mei 7). TEMPO.CO. Retrieved September 3, 2015, from Sisi Lain Ustad Guntur Bumi yang Menghebohkan:

m.tempo.co/read/news/2014/05/07/06 4576102/sisi-lain-ustad-guntur-bumiyang-menghebohkan

detikNews. (2014, Juni 18). Detik News. Retrieved September 3, 2015, from PKS Apresiasi Keberanian Risma Tutup Dolly: m.detik.com/news/berita/2611869/pk s-apresiasi-keberanian-risma-tutupdolly

Djamarah, S. B. (2004). Pola Komunikasi Orang Tua dan Anak dalam Keluarga. Jakarta: PT Rineka Cipta.

Gunawan, I. (2013). Metode Penelitian Kualitatif (Teori dan Praktik). (Suryani, Ed.) Jakarta: Bumi Aksara.

Karlina. (2008). Minat Remaja dalam Kegiatan Keagamaan. Jakarta: UIN Syarif Hidayatulloh.

Liputan6. (2014, Februari 13). Liputan6.com. Retrieved September 3, 2015, from Bukan Kali Ini Saja Ustad Hariri Murka dengan Petugas Soundman:

http://m.liputan6.com/showbiz/read/8 26306/bukan-kali-ini-saja-ustadhariri-murka-dengan-petugassoundman\&ei $=\mathrm{s} 2 \mathrm{j} 19 \mathrm{vGp} \& \mathrm{lc}=\mathrm{id}-$ ID\&s $=1 \& \mathrm{~m}=902 \& \mathrm{ts}=1441248329 \& \mathrm{~s}$ ig=APONPFm6do9fjqNa90tnAOM6 UGYyZCt8Bw 
Ma'arif, B. S. (2010). Komunikasi

Dakwah. (N. S. Nurbaya, Ed.)

Bandung: Remaja Rosdakarya.

Maziyaturrodhiyanah, S. (2008). Analisis Pesan Dakwah Terhadap Teks Syair "Surga-Mu" Karya Band Ungu. Semarang: IAIN Walisongo.

Munir. (2009). Metode Dakwah. Jakarta : Kencana.

Munir, M. (2009). Metode Dakwah. (M. Suparta, \& H. Hefni, Eds.) Jakarta: Kencana.

Poetra, A. e. (2004). Revolusi Nasyid. (D. Riana, Ed.) Bandung: MQS Publishing.

Rizali, N. (2012). Kedudukan Seni dalam Islam. Kajian Seni Budaya Islam , 1, 6.

Saputra, W. (2011). Pengantar Ilmu Dakwah. Jakarta: Raja Grafindo Persada .

Septia, K. (2015, Januari 20). KOMPAS.COM Regional. Retrieved September 3, 2015, from Kepala Sekolah dan Guru Agama Diduga Lakukan Pelecehan Seksual: regional.kompas.com/read/2015/01/2 0/15194781/Kepala.Sekolah.dan.Gur u.Agama.Diduga.Lakukan.Pelecehan. Seksual

Sugiyono. (2013). Metode Penelitian Pendidikan . Bandung : Alfabeta .

Suryabrata, S. (2012). Metodologi Penelitian. Jakarta: Rajawali Pers. 